\title{
Is randomized branch sampling suitable to assess wood volume of temperate broadleaved old-growth forests?
}

\section{Gherardo Chirici ${ }^{\mathrm{a}, *}$, Nicola Puletti $^{\mathrm{b}}$, Riccardo Salvati ${ }^{\mathrm{c}}$, Francesco Arbi $^{\mathrm{d}}$, Catherine Zolli ${ }^{\mathrm{e}}$, Piermaria Corona ${ }^{\mathrm{b}}$}

${ }^{a}$ University of Molise, Dipartimento di Bioscienze e Territorio, Pesche (IS), Italy

${ }^{\mathrm{b}}$ Consiglio per la Ricerca e Sperimentazione in Agricoltura, Forestry Research Centre, Arezzo, Italy

${ }^{\mathrm{c}}$ University of Tuscia, Dipartimento per l'Innovazione nei sistemi Biologici, Agroalimentari e Forestali, Viterbo, Italy

${ }^{\mathrm{d}}$ ASD HUBBLE, Firenze, Italy

${ }^{\mathrm{e}}$ Forestlab.net Network of Forest Geomatics Laboratories, Firenze, Italy

\section{A R T I C L E I N F O}

\section{Article history:}

Received 1 August 2013

Received in revised form 25 September 2013

Accepted 1 October 2013

Available online 26 October 2013

\section{Keywords:}

Horvitz-Thompson estimation

Randomized branch sampling

Old-growth

Precision

Simulation

Tree climbing

\begin{abstract}
A B S T R A C T
Old-growth forests are characterized by the presence of large and very large trees. The estimation of their wood volume and biomass is essential in order to monitor the ecological processes in these stands and their contribution to carbon cycle. However, conventional wood volume estimation techniques based on mensuration of stem diameter at breast height and tree height is most often unfeasible for large and very large trees in old-growth forests because volume models or tables are usually elaborated from trees of smaller size grown up in regularly managed forest stands. Random Branch Sampling (RBS) is often proposed as a possible estimation alternative under such conditions. Starting from the ground level some of the parts of the main trunk and of the branches are sampled and measured to estimate the overall wood volume (or other biophysical variables). The application of RBS in old-growth forests, where tree cutting is usually forbidden or very difficult, requires that the crown of the tree can physically be reached to measure the sampled parts. We argue that under such conditions it is usually preferable to fully measure all the components of the tree crown because RBS estimates are not precise if based on only one sampling path and that, on the other hand, measuring the main trunk and all the branches by tree-climbing consumes the same time as replicating several RBS paths on the same tree. To demonstrate our hypothesis we selected 16 large beech trees located in the old-growth forest of Mount Cimini in Central Italy. Using a modern tree-climbing approach the main trunk and all the branches were measured and recorded in the field. The database was used to simulate RBS paths. Real values from volume census were contrasted with estimates based on RBS. On the whole, RBS estimates based on one single path prove to be highly imprecise. Even for trees characterized by a rather regular form, at least three RBS paths should be repeated on the same tree to maintain the relative standard error under or near $15 \%$. This paper introduces the problem and describes the experimental test. The results are discussed under the perspective of standardized application of the proposed methodology.
\end{abstract}

(c) 2013 Elsevier B.V. All rights reserved.

\section{Introduction}

\subsection{Old-growth forests carbon pool assessment}

Forest inventories are currently evolving towards multipurpose resource surveys and are broadening their scope in several directions: (i) expansion of the target population to include non-traditional attributes such as trees outside the forest and urban forests; (ii) assessment of forest health; (iii) inclusion of additional

\footnotetext{
* Corresponding author. Tel.: +39 0874404138.

E-mail addresses: gherardo.chirici@unimol.it (G. Chirici), nicola.puletti@ entecra.it (N. Puletti), riccardo.salvati@unitus.it (R. Salvati), info@asdhubble.com (F. Arbi), cath.zolli@gmail.com (C. Zolli), piermaria.corona@unitus.it (P. Corona).
}

variables such as biodiversity attributes that are not directly related to timber assessment and wood harvesting; (iv) forest carbon pools and carbon sequestration estimation (Corona et al., 2011).

A large number of ecosystem services are provided by oldgrowth forests. They are important for biodiversity conservation and as carbon reservoirs, for spiritual and aesthetic reasons, but also because they offer to scientists the opportunity of studying ecological processes in nearly undisturbed natural conditions (Wirth et al., 2009). Several approaches for defining an old-growth forest exist, most of which are based on the use of multiple criteria; following the review by Wirth et al. (2009), based on 39 scientific publications, the criterion "large old trees" is ranked first among the different criteria more frequently mentioned in defining an old-growth forest. 